\title{
Ipomoea batatas leaves extract as a green corrosion inhibitor for Q235 steel in HCl solution
}

\author{
Wenguang Zeng ${ }^{1,2}$, Yanyan Xu ${ }^{1,2}$, Pengli Ge ${ }^{1,2}$, Wenwen Xiao ${ }^{1,2}$, Qingshan Liu ${ }^{1,2}$, \\ Zhengyuan Gao ${ }^{3, *}$, Yongbo Yan ${ }^{4, *}$, \\ ${ }^{1}$ SINOPEC Northwest Company of China Petroleum and Chemical Corporation, Urumqi 830011, \\ China; \\ ${ }^{2}$ Key Laboratory of Enhanced Oil Recovery in Carbonate Fractured-vuggy Reservoirs, SINOPEC, \\ Urumqi 830011, China \\ ${ }^{3}$ School of Mechatronics \& Vehicle Engineering, Chongqing Jiaotong University, Chongqing, \\ 400074, China; \\ ${ }^{4}$ School of Oil and Natural Gas Engineering, Southwest Petroleum University, Chengdu 610500 \\ *E-mail: zhengyuangao@cqjtu.edu.cn (Z.Gao); 779265488@qq.com (Y. Yan).
}

Received: 30 June 2021 / Accepted: 2 August 2021 / Published: 10 September 2021

In this study, Ipomoea batatas leaves extract (IBLE) was prepared to control Q235 steel corrosion in 1 $\mathrm{M} \mathrm{HCl}$ solution firstly. The adsorption and corrosion inhibition properties were examined by weight loss, surface topography and electrochemical methods, as well as theoretical simulations. Experimental results reveal that IBLE is a high efficiency mixed-type inhibitor with optimal performance of $96.4 \%$ at $200 \mathrm{mg} / \mathrm{L}$. This contributes to the adsorption of IBLE onto steel samples, which involves both physisorption and chemisorption, consequently forming a strong protective film between steel and acid solution. In addition, molecular simulation results further confirm that IBLE can be effectively adsorbed onto $\mathrm{Fe}(110)$ substrate. Therefore, we developed a novel eco-friendly, efficient corrosion inhibitor for steel in $\mathrm{HCl}$ solution.

Keywords: Corrosion inhibitor; Extract; DFT; Langmuir; Molecular dynamics simulation.

\section{FULL TEXT}

(C) 2021 The Authors. Published by ESG (www.electrochemsci.org). This article is an open access article distributed under the terms and conditions of the Creative Commons Attribution license (http://creativecommons.org/licenses/by/4.0/). 